\title{
Hereditary "pure" spastic paraplegia: a study of nine families
}

\author{
J M Polo, J Calleja, O Combarros, J Berciano
}

\begin{abstract}
The genetic and clinical features of 46 patients in nine families with "pure" hereditary spastic paraplegia are described. Inheritance was autosomal dominant in seven families and autosomal recessive in two. In dominant kinships, five families corresponded to type I with onset below 35 years, and two to type II with onset over 35 years. In early onset dominant families, in spite of apparent complete penetrance before 20 , variable expression and incomplete penetrance occurred. Irrespective of genetic type, serial evaluation revealed that the main symptom consisted of slowly progressive spastic gait, extremely variable in severity, associated in some patients with decreased vibratory sense and micturition disorders generally as late features. In dominant families, the disease tended to be more severe in late onset cases. No patient had symptoms in the upper limbs and plantar responses were flexor in six symptomatic patients. Central motor conduction time studied by transcranial magnetic stimulation was always normal in the upper limbs and increased in the lower limbs in five of the eight patients on whom it was performed. Monomorphic and stereotyped clinical pattern in this series does not support the concept of multisystem involvement of the central nervous system as a hallmark of the disease.
\end{abstract}

( Neurol Neurosurg Psychiatry 1993;56:175-181)

Since the original descriptions more than 100 years ago, ${ }^{12}$ the nosology of hereditary spastic paraplegia (HSP) has been a matter of some controversy. As stated by Appel': "Lorsqu'on parcourt l'abondante littérature de la paraplégie spasmodique familiale, on constate que jamais deux cas ne sont semblables". Indeed the history of HSP appears as if it were two different disorders. One is the so-called "pure" form, with clinical manifestations restricted to corticospinal system degeneration. ${ }^{4}$ The other is made up of a hotchpotch of "complicated" forms where spastic paraplegia coexists with some of the following: amyotrophy, mental retardation, pigmentary retinal degeneration, optic atrophy, extrapyramidal features, cerebellar ataxia, sensory neuropathy or cutaneous lesions. ${ }^{5}$ It remains to be established whether both HSPs are pathogenetically related disorders.

The "pure" form of HSP was first reported by Strümpell in $1880,{ }^{2}$ who shortly afterwards also described the first neuropathological study. ${ }^{6}$ In 1981, Harding ${ }^{4}$ rechecked this "Strümpell's disease" by analysing 22 families from the London area. This wide experience, with 56 patients examined personally, enabled her to establish consistent diagnostic criteria and to determine genetic heterogeneity in the autosomal dominant families. Harding identified two forms of dominant "pure" HSP: type I with an age of onset mostly below 35 years, and type II with onset usually over 35 years.

To date no specific biochemical or genetic marker of "pure" HSP has been found, and diagnosis should be based on clinical findings and positive family history. Most ancilliary diagnostic tests show non-specific results in "pure" HSP, and are only useful for the differential diagnosis of every new case. ${ }^{78}$ As "pure" HSP is an infrequent disease, ${ }^{9}$ personal series are scant. Most investigations are carried out with a small number of patients and any attempt to analyse reported studies comes up against their lack of comparability if minimal diagnostic criteria do not coincide or are simply not mentioned.

In this paper we describe the genetic and clinical features of nine families with "pure" HSP. The study is part of a genetic and clinical investigation on hereditary ataxias, paraplegias and neuropathies, carried out in Cantabria, Spain, from 1974. Geographical and population data as well as epidemiological results have been detailed in previous reports.

\section{Patients and methods \\ Patients}

Proband patients were initially evaluated at the hospital and thereafter systematic family research was carried out. All cooperative atrisk family members, parents, siblings and children of patients were visited in hospital or at home. In most of the affected members and in selected at-risk individuals, serial clinical examinations, yearly or less frequently, were performed.

Diagnostic criteria were those of Harding, ${ }^{4}$ that is, progressive spastic paraplegia with pyramidal signs in lower limbs, patients not being excluded if they had minimal ataxia in the upper limbs or distal wasting of moderate degree if symptoms had been present for more than 10 years. In this study, an asymptomatic patient was defined as an at-risk relative in whom knee and ankle hyperreflexia and extensor plantar responses were present, as verified by two independent examiners (JMP and JB). No single cases were included here unless objective evidence of disease in at least one 
additional family member had been found.

In addition to the nine index patients, 109 relatives were examined of whom 37 were found to be affected. Thus a total of 46 affected members were personally examined. A further 10 living relatives were affected as a result of their history at the beginning of the study. Patients I-1 and I-2 in family E were examined in 1929 by Dr José M Aldama Truchuelo in the former "Casa de Salud Valdecilla", and clinical data were obtained from medical records.

A three point functional grading scale, modified from Behan and Maia, ${ }^{10}$ was adopted for the study. Grade 1 corresponds to an asymptomatic patient who had pyramidal signs in the lower limbs with normal or only slightly spastic gait; grade 2 refers to a patient with spastic gait, able to walk independently with or without support; and grade 3 if the patient was chairbound or bedridden.

\section{Electrophysiological techniques}

We concentrated here on patients in whom central motor conduction time (CMCT) was studied. Other electrophysiological features, including motor and sensory nerve conduction studies and somatosensory and brainstem auditory evoked potentials, will be published later.

Nerve conduction velocity and electromyography were performed according to the method described in an earlier study. ${ }^{11}$ Transcranial stimulation was carried out with a Magstim 200 (Novametrix) magnetic stimulator following the technique described by Claus. ${ }^{12}$ Muscle recordings were made on an electromyograph (Medelec MS20) from the abductor pollicis brevis in the hand and extensor digitorum brevis in the foot. CMCT was calculated on F-wave latency. Results were compared with those from 15 subjects with no history of neurological disorders (6 men, 9 woman; 27-40 years, mean (SD) $30 \cdot 7(4 \cdot 9)$; height $150-192 \mathrm{~cm})$. The normal limits were taken as mean (SD) $2 \cdot 5$. The purpose and methodology of the studies were explained to each patient and were performed with their explicit permission.

\section{Results}

\section{GENETIC FEATURES}

Autosomal dominant families

In seven families (fig 1 ) the disease occurred in several members of consecutive generations, and an autosomal dominant inheritance may be deduced from pedigrees. Male-to-male transmission was present in six, and in the last, family $F$, the symptoms were equally severe in both sexes. No significant difference in distribution between sexes was observed if all those affected, examined or not, were considered; there was, however, a predominance of men, 45 as opposed to 29 women (Chi square $=1.75 ; p>0.05)$. The mean (SD) age of onset established from the 33 patients about whom information was available was 29.97 (17.47) (range 3-63) years. Inspection of the mean age of onset in each family (table 1) suggests that two different diseases may be present. Comparison of these figures by the Kruskal-Wallis test, ${ }^{13}$ infers that the autosomal dominant "pure" HSP is caused by more than one gene ( $S=20.823 ; p<0.005)$. The seven families could be assigned to one of the two groups proposed by Harding, ${ }^{4}$ five belonging to type I and two to type II. Patient B-IV-12 was an obvious exception. This man from an early-onset family was found to be normal between 28 and 41 years, but after the age of 42 developed increased running difficulties. Two years later he showed an unequivocal slinical picture, very similar to that of his siblings. Ancillary studies in this patient, including CSF examination and MRI proved negative.

As an approximation to genetic counselling in early-onset families, we have analysed the siblings at-risk in which all siblings were examined, divided in two groups depending on whether the examination took place before or after the age of 20 (table 2). This limit was chosen provided that mean and median age of onset in type I were between $15-20$ years. The proportion of affected to unaffected cases did not differ from the expected $50 \%$. Five of the 13 affected were asymptomatic, four of them in the younger group.

Incomplete penetrance based on history was determined in the early-onset family $B$, in which three apparently unaffected men had transmitted the disease. None of them could be examined as they had died at 78, 53 and 34 years, respectively, before the start of this study. But in family D, patients D-III-12 and D-III-19, two women both daughter and mother of affected and examined women, were asymptomatic and had a normal neurological examination at the ages of 52 and 53.

Although homozygosity could be invoked for members in the second generation in family $\mathrm{E}$ (fig 1), none of the three affected subjects of the sibship had by history unusual clinical features that would not have been expected in heterozygotes.

\section{AUTOSOMAL RECESSIVE FAMILIES}

In two families the disease was confined to one generation (fig 2). In family $\mathrm{H}$ a man and two women were affected. Two siblings were stillborn and two others had died during the first year of life, and no further information about them was available. The father had died at the age of 80 , before the start of the study, but he did not show any symptoms to suggest HSP before his death. The mother was neurologically normal when examined at the age of 81. Because the parents were first cousins and no other case was known in the family, it was thought that recessive inheritance was very likely. In family I, where three out of eight siblings were found to be affected, no other case was known among the ancestors and the parents, who were consanguineous, had a normal neurological examination at the age of 75 and 74 years.

There were three men and three women affected in both families and the onset occurred in the first decade of life in all of them 
Figure 1 Pedigrees of seven families ( $A$ to $G$ ) with "pure" HSP and autosomal dominant inheritance. Symbols with horizontal marks

correspond to examined individuals.

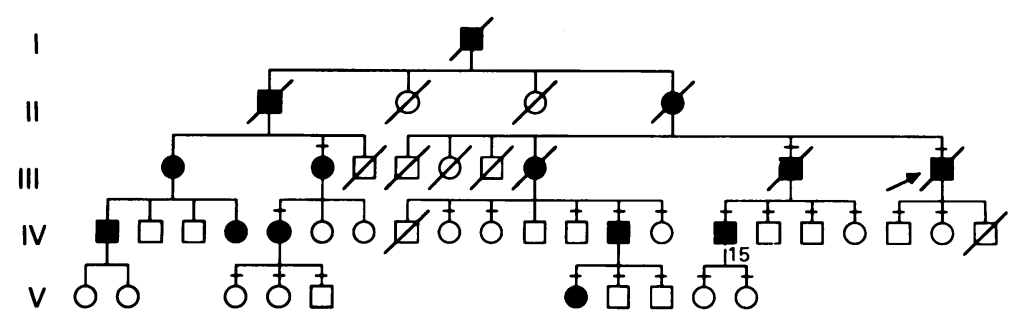

FAMILY A

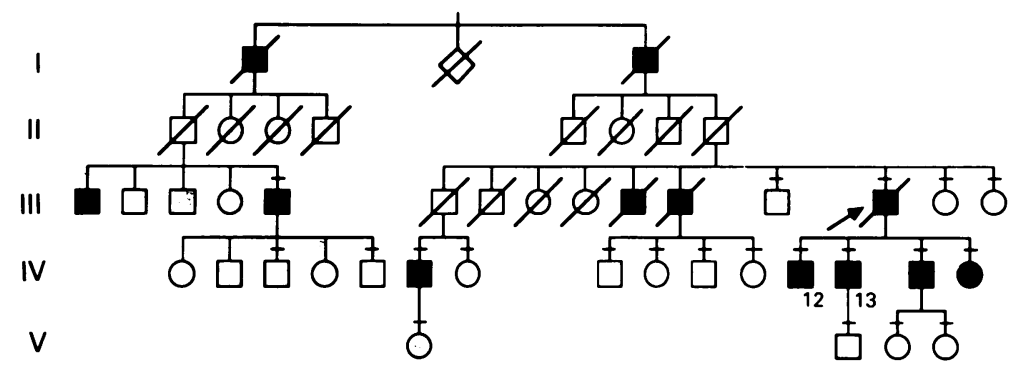

FAMILY B

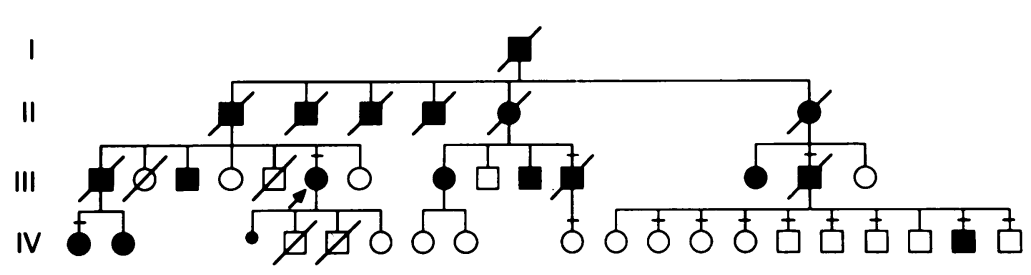

FAMILY C

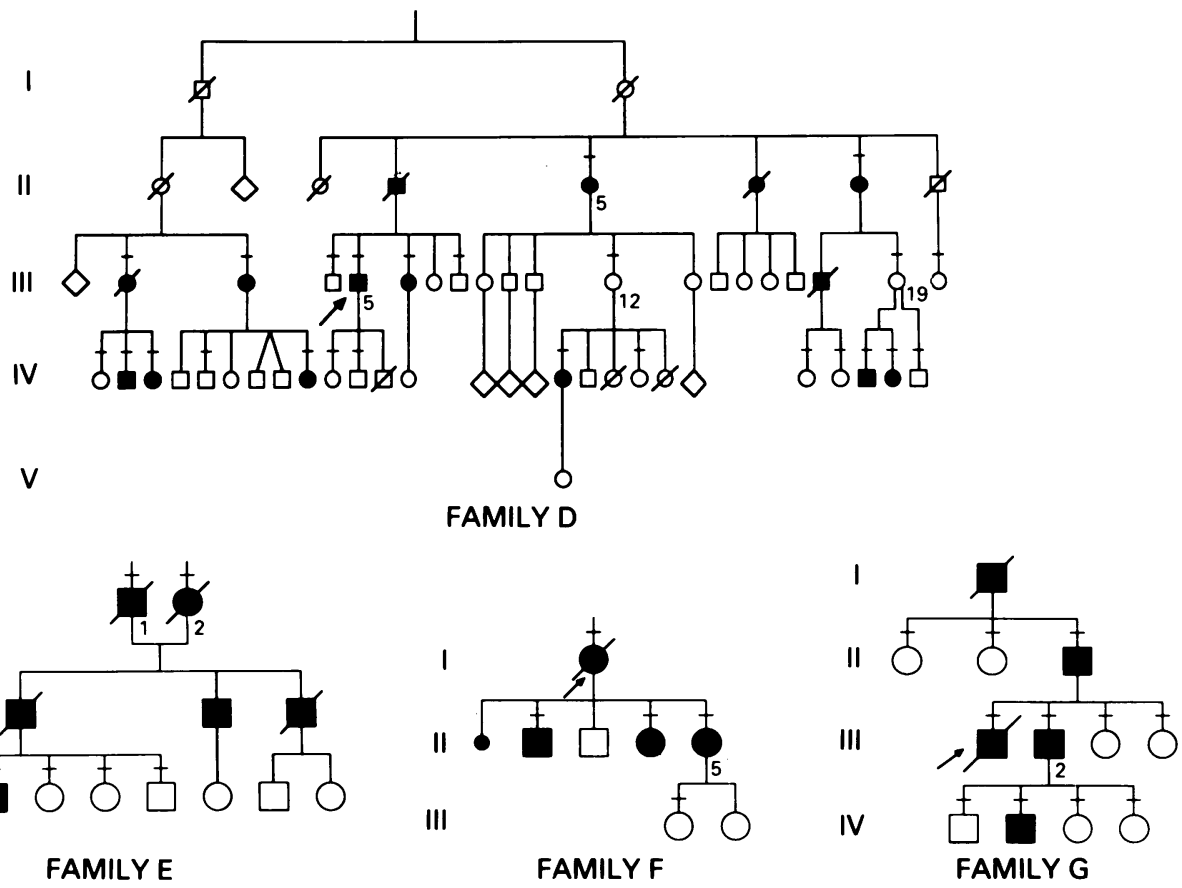

[mean (SD) 6.67(0.52) years; range 6-7]. All six were unmarried and had no descendants.

\section{Presenting symptoms}

In the 31 symptomatic patients, both dominant and recessive, the first manifestation of the disease was insidious and concerned the lower limbs. It was described in a diverse manner by patients as abnormality of gait, running or jumping difficulties, clumsiness in going up and down slopes, or stiffness of the legs. In 11 patients the disorder was first noticed by their relatives. Seven patients had prematurely worn out shoes and this seemingly minor complaint was characteristically interpreted by the patients themselves and their relatives as the first indication of the family disease. Motor delay occurred in none of the 30 patients for whom information was available.

Fifteen patients of the dominant families, 12 in type I and three in type II, were asymptomatic at first examination. All were unaware of a gait problem and came to us to complete the 
Table 1 Autosomal dominant "pure" HSP: age of onset (years)

\begin{tabular}{|c|c|c|c|c|c|c|c|}
\hline Family & $\begin{array}{l}\text { A } \\
35 \\
63 \\
50 \\
61 \\
38 \\
35 \\
45\end{array}$ & $\begin{array}{l}\text { B } \\
10 \\
15 \\
18 \\
15 \\
18 \\
42\end{array}$ & $\begin{array}{l}C \\
30 \\
60 \\
30 \\
50 \\
50 \\
50 \\
37\end{array}$ & $\begin{array}{l}\mathrm{D} \\
15 \\
54 \\
22 \\
18 \\
14\end{array}$ & $\begin{array}{c}\mathrm{E} \\
15 \\
18 \\
9\end{array}$ & $\begin{array}{l}\mathrm{F} \\
10 \\
3\end{array}$ & $\begin{array}{l}G \\
16 \\
23 \\
20\end{array}$ \\
\hline Mean & $46 \cdot 71$ & $19 \cdot 67$ & $43 \cdot 85$ & $24 \cdot 6$ & $14 \cdot 0$ & 6.5 & $19 \cdot 67$ \\
\hline
\end{tabular}

Table 2 Early-onset AD "pure" HSP: persons at risk at the time of study

\begin{tabular}{lllll}
\hline Age (years) & $\begin{array}{l}\text { Normal } \\
\text { examination }\end{array}$ & Affected & $\begin{array}{l}\text { Percent } \\
\text { affected }\end{array}$ & $p$ \\
\hline$>20$ & 17 & 8 & $32 \%$ & NS \\
$<20$ & $99^{\star}$ & 5 & $35 \cdot 7 \%$ & NS \\
Total & 26 & 13 & $33 \cdot 3 \%$ & NS \\
\hline
\end{tabular}

AD: autosomal dominant; NS: not signficantly different from the expected $50 \%$ by Chi-square test; ${ }^{\star}$ three individuals under ten years.

study of the families. After direct questioning, seven shared vague complaints in the lower limbs such as running or jumping difficulties or ill-defined discomfort in the feet. Follow up of these asyptomatic patients enabled us to be present in five cases as their symptoms developed.

\section{CLINICAL FINDINGS}

Autosomal dominant patients

Table 3 summarises the occurrence of some selected clinical features. Spastic gait was the prominent sign in all symptomatic patients, with an exceedingly variable degree of severity. Twenty six early-onset patients had normal gait or walked independently as opposed to $25 \%$ who were chair-bound in the late-onset group. Characteristically this dynamic hypertonia was associated with scant motor deficit and moderate spasticity when the tonus was examined at rest. Both resting hypertonia and pyramidal weakness were more frequent in type II although only the former shows a statistically significant difference. Foot deformity predominated in type $I$, consisting of pes planus in one. These differences occurred when the clinical course in early-onset patients was longer (table 3). Six symptomatic patients in both types had flexor plantar responses. Super-

Figure 2 Pedigrees of two families ( $H$ and I) with "pure" HSP and autosomal recessive inheritance. Broken and double lines indicate consanguinity.

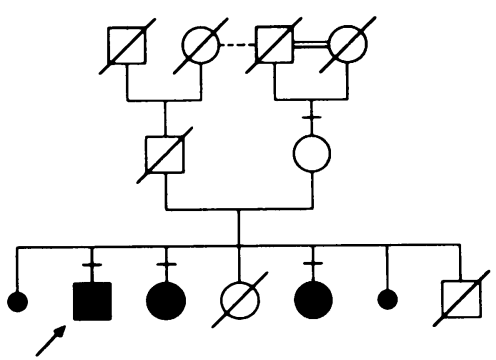

FAMILYH

I

III

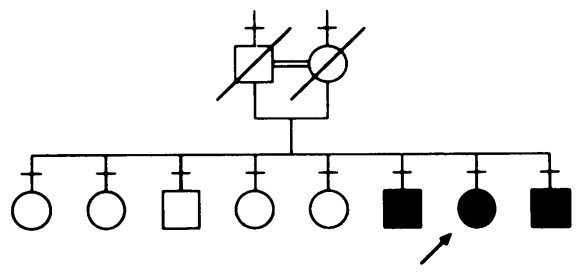

FAMILYI ficial abdominal reflexes were unobtainable in 10 out of 28 patients who had such an examination.

Reduction of vibration sense in the feet, found in 10 patients, was the only sensation abnormality. It was more frequent in type II, but the difference was not significant. In earlyonset patients, the mean (SD) duration of disease was longer in those with sensory loss, $37(29.93)$ years, than in those with normal sensory examination, $9.69 \quad(14.49)$ years $(p<0.005)$. In late-onset patients the difference was not significant, $14.4(11.08)$ years as opposed to $6.71(5.22)$ years $(p>0.05)$. Joint position sense was normal in all patients as was superficial sensation. With the upper limb findings, amyotrophy, pyramidal weakness and ataxia were absent in all patients, and although myothatic hyperreflexia was more frequent in type II (table 3), the difference was not significant. Seven patients had urinary symptoms, which consisted of permanent incontinence in one and urgent micturition in the other six. Anal control was normal in all patients. Sexual involvement was not analysed because it was not assessed in most cases.

The size of samples precludes any comparison between the presence and duration of diverse symptoms and the duration of disease if subtypes were to be considered. Two patients in type I and three in type II were chair-bound, having reached this level of severity between the ages of 50 and 75 . But in the late-onset patients the duration of the disease was 9,20 and 24 years, whereas in the early-onset it was 40 and 60 . Similarly, comparison of severity between sexes was not feasible; the only remarkable difference was the higher number of asymptomatic women in type I, 9 as opposed to 3 men. Nine patients had died since the start of the study. Unfortunately post mortem examination was unavailable in any of the cases.

AUTOSOMAL RECESSIVE PATIENTS

The six patients in the recessive families experienced a gradual deterioration of the lower extremities that had stabilised after 10-20 years, but no major clinical differences were found in relation to dominant cases (table 3). Gait disorder was severe in all, and at-resthypertonia and weakness predominated in those with a longer duration of symptoms. All had pes cavus, whereas reduction of vibratory sensation occurred only in two patients in family $\mathrm{I}$. The three siblings in family $\mathrm{H}$ had had unmodified urinary urgency and frequency for more than 20 years. All showed asymptomatic hyperreflexia in upper limbs.

\section{Electrophysiological studies}

Eight dominant patients (six men, two women) had motor conduction studies (table 4). All but one belonged to early-onset families. Patient G-IV-2 was the only asymptomatic one in this group. Only two patients had brisk upper limb reflexes. Electromyography of abductor pollicis brevis and extensor digitorum brevis muscles did not reveal any relevant abnormalities. Motor nerve conduction studies of median and 
Table 3 "Pure" HSP: summary of clinical features

\begin{tabular}{|c|c|c|c|c|}
\hline & $\begin{array}{l}A R \\
(n=6)\end{array}$ & $\begin{array}{l}\text { AD Type I } \\
(n=28)\end{array}$ & $\begin{array}{l}\text { AR Type II } \\
(n=12)\end{array}$ & $p(I \text { vs } I)^{2}$ \\
\hline Duration $^{1}$ & $31.33(12.01)$ & $28 \cdot 67(19 \cdot 74)$ & $11 \cdot 33(9 \cdot 15)$ & $<0.025^{\star}$ \\
\hline Disability score: & & & & \\
\hline 1 & 0 & 12 & 3 & NS \\
\hline 2 & 3 & 14 & 6 & NS \\
\hline 3 & 3 & 2 & 3 & NS \\
\hline Urinary symptoms & 3 & 4 & 3 & NS \\
\hline Upper limbs hyperreflexia & 6 & 7 & 5 & NS \\
\hline Lower limbs & & & & \\
\hline $\begin{array}{l}\text { Pes cavus } \\
\text { Hypertonia }\end{array}$ & 6 & 18 & 4 & NS \\
\hline moderate or severe & 2 & 8 & 8 & $<0.05$ \\
\hline $\begin{array}{l}\text { Weakness } \\
\text { moderate or severe }\end{array}$ & 4 & 4 & 5 & NS \\
\hline Decreased/absent & 4 & & & 10 \\
\hline ankle jerks & 1 & 1 & 1 & NS \\
\hline Plantar response flexor & 0 & 4 & 2 & NS \\
\hline Vibration sense decrease & 2 & 5 & 5 & NS \\
\hline
\end{tabular}

AR: autosomal recessive; $\mathrm{AD}$ : autosomal dominant; ' Only symptomatic patients when firs examined; ' comparisons by Fisher's exact test or ^Student's $t$ test; NS: not significant.

Table 4 Autosomal dominant "Pure" HSP: central motor conduction times

\begin{tabular}{|c|c|c|c|c|c|c|}
\hline \multirow[b]{3}{*}{ Case } & \multirow{3}{*}{$\begin{array}{l}\text { Age } \\
\text { (years) }\end{array}$} & \multirow{3}{*}{$\begin{array}{l}\text { Duration } \\
\text { (years) }\end{array}$} & \multirow{3}{*}{$\begin{array}{l}\text { Disability } \\
\text { score }\end{array}$} & \multicolumn{3}{|l|}{$C C T$} \\
\hline & & & & \multirow[t]{2}{*}{$A P B(\mathrm{~ms})$} & \multicolumn{2}{|c|}{$E D B$ (ms) } \\
\hline & & & & & Right & Lefi \\
\hline $\begin{array}{l}\text { A-IV-15 } \\
\text { B-IV-12 } \\
\text { B-IV-13 } \\
\text { D-II-5 } \\
\text { D-III-5 } \\
\text { F-II-5 } \\
\text { G-III-2 } \\
\text { G-IV-2 } \\
\text { Upper lim }\end{array}$ & $\begin{array}{l}63 \\
46 \\
41 \\
88 \\
65 \\
27 \\
50 \\
24 \\
\text { ontrols, }\end{array}$ & $\begin{array}{l}18 \\
4 \\
26 \\
73 \\
43 \\
6 \\
30 \\
\text { asympt } \\
\text { (SD) } 2 \cdot 5\end{array}$ & $\begin{array}{l}2 \\
2 \\
2 \\
3 \\
2 \\
2 \\
2 \\
1\end{array}$ & $\begin{array}{l}4 \cdot 2 \\
7 \cdot 7 \\
7 \cdot 2 \\
8 \cdot 1 \\
8 \cdot 2 \\
6 \cdot 7 \\
5 \cdot 8 \\
5 \cdot 5 \\
9 \cdot 4^{\star}\end{array}$ & $\begin{array}{l}16 \cdot 6 \\
16 \cdot 9 \\
21 \cdot 2 \\
17 \cdot 3 \\
16 \cdot 3 \\
10 \cdot 1 \\
15 \cdot 0 \\
11 \cdot 1 \\
16 \cdot 8^{\star \star}\end{array}$ & $\begin{array}{l}16 \cdot 7 \\
17 \cdot 7 \\
23 \cdot 7 \\
17 \cdot 5 \\
16 \cdot 9 \\
10 \cdot 6 \\
17 \cdot 9 \\
15 \cdot 4 \\
16 \cdot 8^{\star \star \star}\end{array}$ \\
\hline
\end{tabular}

CCT: central conduction time; ADP: abductor pollicis brevis; EDB: extensor digiti brevis *control values $(N=30): 6 \cdot 18(1 \cdot 29) ;{ }^{\star \star}$ control values $(\mathrm{N}=15): 10 \cdot 3(2 \cdot 6) ;{ }^{\star \star \star}$ control values $(\mathrm{N}=15): 11 \cdot 3(2 \cdot 2)$.

peroneal nerves were normal. The results of central conduction times appear in table 4 . CMCT in the upper limbs was always within the normal range; bilateral examinations were only done in the four patients who were first examined. Responses evoked in the lower limbs were recorded on both sides in all eight patients; CMCT was increased bilaterally in three cases and unilaterally in two, and normal in the remainder.

\section{Discussion}

In this series, "pure" HSP was transmitted as an autosomal dominant gene in seven out of nine families, a proportion close to that reported by other authors. ${ }^{414}$ Bell and Carmichael ${ }^{15}$ found 49 probable recessively inherited pedigrees among 74 published families, but it is clear that their material was clinically heterogeneous. X-linked inherited "pure" HSP is exceedingly rare $^{5}$ and only one family with apparent certainty has been described. ${ }^{16}$

Genetic heterogeneity regarding age of onset seems a well established fact in autosomal dominant "pure" HSP. ${ }^{4}$ Most of the patients in this series conform to the cut-off point at 35 years proposed by Harding. ${ }^{4}$ Schady and Sheard ${ }^{17}$ recently found that 20 years might be a better limit to avoid overlap between early and late-onset types. This lack of concensus may in part be explained by the difficulty in establishing the precise time of onset in a disease with insidious beginning of symptoms. ${ }^{18}$ In fact, the age at which the degenerative process becomes apparent is rarely or never the true age of onset of the disease. ${ }^{15}$ In our early-onset dominant patients, penetrance was apparently complete before the age of 20 , and therefore it seems possible to recognise the disease even when patients are still asymptomatic. Because some exceptions may occur, as this study indicates, it should be borne in mind that the absence of signs in an individual at-risk does not rule out the likelihood of becoming ill, irrespective of the age at which examination is performed. This variable expression in relation to age of onset, not uncommon in dominantly inherited disorders, may be complicated still further due to the incomplete penetrance of the gene. Such a possibility in "pure" HSP was suggested by Burdick et al, ${ }^{19}$ based on the fact that some children became symptomatic before their parents, who later also became affected. But in the family that Burdick studied the disparity of age of onset lay on the earliness of the disease in the youngest generation, giving the impression that genetic anteposition and variable expression were perhaps confused with incomplete penetrance. In autosomal dominant disorders an incomplete penetrance occurs when a carrier of the specific gene shows no clinical sign of it, ${ }^{20}$ but is able to transmit it. Generation leaps based on family history that occurred in our family $B$, have occasionally been reported. ${ }^{1021-24}$ But the high proportion of asymptomatic patients in "pure" HSP make it risky to consider as unaffected an ancestor who has not been examined. Bickerstaff ${ }^{21}$ and Bone $e t$ $a l^{25}$ reported objective instances of incomplete penetrance, but we agree with Harding ${ }^{5}$ that the clinical picture in affected descendants was, to say the least, atypical. On the other hand, we have found in an early-onset family two healthy women, descendants and mothers of examined patients. Provided that maternity is always confirmed, we conclude that, from a practical point of view, they constitute two cases of incomplete penetrance. Genetic counselling in "pure" HSP therefore sometimes becomes a difficult task. A specific genetic marker is a pressing need.

Apart from the variability in age of onset, the clinical features of "pure" HSP are quite stereotyped. ${ }^{4}$ But some aspects deserve comment. We were surprised by the high number of asymptomatic, but clinically affected, patients when a systematic study of the families was carried out. Already present in earlier descriptions, ${ }^{26}$ the existence of asymptomatic patients in "pure" HSP was specifically mentioned by Bickerstaff $^{21}$ and Ozsvath. ${ }^{27}$ Harding $^{4}$ found that $23 \%$ of her early-onset dominant patients were asymptomatic; intriguingly, in our series there were some even in late-onset families. The inclusion of those probable affected ${ }^{28}$ as affected cases implies the risk of an exaggerated diagnostic enthusiasm, ${ }^{21}$ but serial examinations eventually lead to an unequivocal diagnosis. We come to the conclusion that myotatic hyperreflexia and extensor plantar responses, if consistenly assessed, are enough to assure the presence of the gene in an at-risk person. This fact also emphasises the need and usefulness of examining the greatest number of individuals in every new family. 
Once started, the gait disorder increases slowly to a variable severity level. There is a characteristic predominance of dynamic spasticity over pyramidal weakness and at-rest hypertonia. This spasmodic pseudoparalysis, already recognised in early studies, ${ }^{2}$ is associated with flexor plantar responses in some patients with an important handicap. Appel ${ }^{3}$ interpreted this particular combination of signs as the result of an area 6 syndrome, an attractive hypothesis not demonstrated for the moment. As occurred in six patients of our series, flexor plantar responses have been reported in some patients with an otherwise definite clinical picture; ${ }^{212329-31}$ this fact militates against including Babinski's sign as an obligatory criterion of the disease. ${ }^{8}$

In spite of the fact that degeneration of the Goll columns is a constant pathological finding in "pure" HSP, ${ }^{10}$ only a quarter of our patients showed involvement of propioceptive sensation, a proportion which coincides with that found by Harding. ${ }^{4}$ Such clinico-pathological dissociation has also been described in olivopontocerebellar atrophy. ${ }^{32}$ In "pure" HSP it characteristically consists of a loss of vibratory perception in the legs and feet with an almost always normal position sense, and is usually a late clinical feature.

A more or less marked pes cavus was a sign present in more than half of the patients, and in dominant families it was more frequent in those with an earlier onset. It has been stated that foot deformity in HSP may be different from other neurological conditions in that the arching disappears on standing. ${ }^{21}{ }^{33}$ Most of the patients in this series had slight deformities, but if pronounced it was indistinguishable from that found in other spinocerebellar syndromes. Incidentally, one patient had pes planus. $^{2934}$ Late involvement of the upper limbs has been considered as an infrequent but characteristic feature in "pure" HSP." Increased upper limb reflexes may be present, as in a third of our patients, even in the early stages. ${ }^{24}$ But none of them had pyramidal weakness and in Harding's series ${ }^{4}$ only two patients showed symptoms in the upper limbs. Even though pyramidal signs can be detected in some, it therefore seems clear that brachial manifestations are exceptional. Philip ${ }^{35}$ reported for the first time urinary symptoms in "pure" HSP. Although these symptoms had been considered infrequent, ${ }^{36}$ nearly half of the patients in Harding's series ${ }^{4}$ had urinary urgency or urinary frequency. In our series 10 patients had impaired urinary function, generally as a late clinical feature. ${ }^{4}$

The impression, mentioned by Bickerstaff, ${ }^{21}$ that the earlier the onset the faster its evolution, was not borne out by Harding. ${ }^{4}$ Comparing type I with type II patients she found that the clinical picture is more serious if symptoms begin after 35 years. We found a similar tendency, even if statistical comparison was not significant, considering the larger duration of symptoms in our early-onset patients. This was supported by the additional evidence that type II patients become chair-bound earlier, ${ }^{4}$ in spite of the fact that here again the small size of our sample hindered a statistical analysis.

Reports on transcranial stimulation of the motor cortex in "pure" HSP are scarce. Using electrical stimulation, Thompson et $a l^{37}$ found mild prolongation of latencies to the electromyographic responses, only in one leg, in two men with a static spastic paraparesis. Also with electrical stimulation, Pelosi $e t a l^{38}$ found abnormalities consisting of absent responses, reduced amplitude, slowed central conduction velocity or prolonged central conduction time in the legs, in all 10 patients they studied. By using transcranial magnetic brain stimulation, Claus $e t a l^{39}$ found that CMCT was normal with upper limb recordings in eight out of 10 patients, whereas it was abnormal in all four patients in whom it was recorded from the tibialis anterior muscle. The study by Schady $e t$ $\mathrm{al}^{7}$ in a larger group of patients, failed to establish a consistent pattern of changes using magnetic brain stimulation, in spite of the high number of abnormalities they found. In the same way, our results indicate that even if CMCT in "pure" HSP is increased in a proportion of patients, central motor conduction studies lack value in detecting subclinical lesions in most patients with HSP.

The term "pure" when applied to "pure" HSP is more than semantic because it refers to a clinical reality. As this series shows, the patients develop a stereotyped clinical picture, exclusively made up of increasing spastic gait. This clinical picture has nothing to do with the reported "complicated" forms of HSP. ${ }^{58}$ It is clear from the published neuropathological studies carried out in "pure" HSP $^{8}{ }^{10}$ that this entity is far from being the model of a sole corticospinal tract degeneration. The enigma now is whether a subclinical involvement exists affecting all the many neuronal systems as electrophysiological investigations seem to suggest. In addition to corticospinal pathNays $^{73-39}$ and dorsal columns, ${ }^{3840-43}$ both known to be affected in "pure" HSP, there is evidence of involvement of afferent pathways nediating pain and thermal sensibility, ${ }^{17}$ vis$\mathrm{ual}^{4144-46}$ and auditory ${ }^{4146}$ pathways, cerebellar control systems ${ }^{46}$ and even neuropsychological function-maintaining structures. ${ }^{46}$ It may be that a greater part of the nervous system is involved in the pathological process. Further investigations, including molecular genetic studies, will be required to provide a definite answer to this still puzzling disease.

We are very grateful to Dr B Ruiz Blanco for translation of German papers and to John Hawkins for stylistic revision of the manuscript. The study was supported in part by Fondo de Investigaciones Sanitarias, grant 88/1502.

1 Seeligmüller A. Sklerose der Seitenstränge des Rückenmarks bei vier Kindern derselben Familie. Dtsch Med Wochenschr 1876;2:185-6.

2 Strümpell A. Beiträge zur Pathologie des Rückenmarks. Arch Psychiatr Nervenkr 1880;10:676-717.

3 Appel L. Etudes sur la paraplégie spasmodique familiale. Analogie avec le syndrome de l'aréa 6. Acta Neurol Belg 1951;49:415-32.

4 Harding AE. Hereditary "pure" spastic paraplegia: a clinical and genetic study of 22 families. F Neurol Neurosurg Psychiatry 1981;44:871-83.

5 Harding AE. The hereditary ataxias and related disorders. Edinburgh: Churchill Livingstone, 1984. 
6 Strümpell A. Ueber eine bestimmte Form der primären combinierten Systemerkrankung des Rückenmarks. Arch Psychiatr Nervenkr 1886;1 7:217-38.

7 Schady W, Dick JPR, Sheard A, Crampton S. Central motor conduction studies in hereditary spastic paraplegia. $\mathcal{F}$ Neurol Neurosurg Psychiatry 1991;54:775-9.

8 Bruyn RPM, Scheltens PH. Hereditary spastic paraparesis (Strümpell-Lorrain). In: de Jong JMBV, ed. Handbook of clinical neurology, vol. 15 (59). Amsterdam: Elsevier, clinical neurolog.

9 Polo JM, Calleja J, Combarros O, Berciano J. Hereditary ataxias and paraplegias in Cantabria, Spain. An epide-

miological and clinical study. Brain $1991 ; 114: 855-66$.
Behan WMH, Maia M. Strümpell's familial spastic paraplegia: genetics and neuropathology. $\mathcal{F}$ Neurol Neurosurg Psychiatry 1974;37:8-20.

11 Berciano J, Combarros O, Figols J, et al. Hereditary motor and sensory neuropathy type II. Clinicopathological study of a family. Brain 1986;109:897-914.

12 Claus D. Central motor conduction: method and normal results. Muscle Nerve 1990;13:1125-32.

13 Emery AEH. Methodology in medical genetics. An introduction to statistical methods. 2nd ed. Edinburgh: Churchill Livingstone, 1986

14 Holmes GL, Shaywitz BA. Strümpell's pure familial spastic paraplegia: case study and review of the literature. paraplegia: case study and review of the

15 Bell J, Carmichael EA. On hereditary ataxia and spastic paraplegia. Treasury of human inheritance 1939;4: 141-281.

16 Keppen LD, Leppert MF, O'Connell P, et al. Etiological heterogeneity in X-linked spastic paraplegia. Am $\mathcal{F}$ Hum Genet 1987;41:933-43.

17 Schady W, Sheard A. A quantitative study of sensory function in hereditary spastic paraplegia. Brain 1990;113:709-20.

18 Schoenberg BS. Epidemiology of the inherited ataxias. $A d v$ Neurol 1978;21:15-32.

19 Burdick AB, Owens LA, Peterson CR. Slowly progressive autosomal dominant spastic paraplegia with late onset, variable expression and reduced penetrance: a basis for diagnosis and counselling. Clin Gent 1981;19:1-7.

20 Michels VV, Dyck PJ. Mendelian inheritance and basis of classification of hereditary neuropathy with neuronal classification of hereditary neuropathy with neuronal atrophy and degeneration. In: Dyck PJ, Thomas PK, Lambert EH, Bunge R, eds. Peripheral neuropath
2nd ed. Philadelphia: Saunders 1984:1512-24.

21 Bickerstaff ER. Hereditary spastic paraplegia. I Neurol Neurosurg Psychiatry 1950;13:134-45.

22 Thurmon TF, Walker BA. Two distinct types of autosomal dominant spastic paraplegia. Birth Defects Original Article Series 1971;7:216-18.

23 Sack GH, Huether CA, Garg N. Familial spastic paraplegia. Clinical and pathologic studies in a large kindred. fohn Hopkins Med f 1978;143:117-21.

24 Grassin D-Y. La paraplégie spasmodique familiale (Maladie de Strümpell-Lorrain). A propos de 11 généalogies (MD thesis). University Claude-Bernard of Lyon, 1975.

25 Bone I, Johnson RH, Ferguson-Smith MA. Occurrence of familial spastic paraplegia in only one of monozygous familial spastic paraplegia in only one of monozygous

26 Newmark L. A contribution to the study of the family form of spastic paraplegia. Am $\mathcal{F} \mathrm{Med} S c i$ 1893;55:432-40.
27 Ozsváth K. Paralysis spinalis spastica familiaris. Dtsch $Z$ Nervenheilk 1968;193:287-323.

28 Boustany R-MN, Fleischnick E, Alper CA, et al. The autosomal dominant form of "pure" familial spastic paraplegia: clinical findings and linkage analysis of a large pedigree. Neurology 1987;37:910-15.

29 Kühn H. Klinische Beiträge zur Kenntniss der hereditären und familiären spastischen Spinalparalyse. Dtsch $Z \mathrm{Ner}$ venheilk 1902;22:132-52.

30 Punton J. Hereditary spastic paraplegia. Report of seven cases in two families. F Nerv Ment Dis 1909;36: $588-600$.

31 Mason VR, Rienhoff WF. Hereditary spastic paraplegia. fohns Hopkins Hosp Bull 1920;31:215-17.

32 Berciano J. Olivopontocerebellar atrophy. A review of 117 cases. I Neurol Sci 1982;53:253-72.

33 Tooth HH. Hereditary spastic paraplegia. St Barth Hosp Rep $1891 ; 27: 7-14$

34 Kraft-Ebbing R. Ueber infantile familiäre spastische Spinalparalyse. Dtsch Z Nervenheilk 1900;17:87-98.

35 Philip RW. Primary spastic paralysis and pseudo-hypertrophic paralysis in different members of the same family with probable heredity in both. Brain 1886;8:520-7.

36 Sutherland JM. Familial spastic paraplegia. In: Vinken PJ, Bruyn GW, ed. Handbook of clinical neurology, vol 22. Amsterdam: North-Holland, 1975:421-31.

37 Thompson PD, Day JC, Rothwell JPR, et al. The interpretation of electromyographic responses to electrical stimulation of the motor cortex in diseases of the upper motor neurone. I Neurol Sci 1987;80:91-110.

38 Pelosi L, Lanzillo B, Perretti A, Santoro L, Blumhardt L, Caruso G. Motor and somatosensory evoked potentials in hereditary spastic paraplegia. I Neurol Neurosurg Psychiatry 1991;54;1099-102.

39 Claus D, Waddy HM, Harding AE, Murray NMF, Thoma PK. Hereditary motor and sensory neuropathies and hereditary spastic paraplegia: a magnetic stimulation study. Ann Neurol 1990;28:43-49.

40 Thomas PK, Jefferys JGR, Smith IS, Loulakakis D. Spinal somatosensory evoked potentials in hereditary spastic paraplegia. $f$ Neurol Neurosurg Psychiatry 1981;44: 243-6.

41 Pedersen L, Trojaborg W. Visual, auditory and somatosensory pathway involvement in hereditary cerebellar ataxia, sory pathway involvement in hereditary cerebellar ataxia, Friedreich's ataxia and familial spastic parapleg
encephalogr Clin Neurophysiol 1981;52:283-97.

42 Dimitrijevic MR, Lenman JAR, Prevec T. Wheatly K. A study of posterior column function in familial spastic paraplegia. $\mathcal{f}$ Neurol Neurosurg Psychiatry 1982;45:46-9.

43 Uncini A, Treviso M, Basciani M, Gambi D. Strümpell' familial spastic paraplegia: an electrophysiological demonstration of selective central distal axonopathy. Electroencephalogr Clin Neurophysiol 1987;66:132-6.

44 Happel LT, Rothschild H, Garcia C. Visual evoked potentials in two forms of hereditary spastic paraplegia. Electroencephalogr Clin Neurophysiol 1980;48:233-6.

45 Livingstone IR, Mastaglia FL, Edis R, Howe JW. Pattern visual evoked responses in hereditary spastic paraplegia. $f$ veurol Neurosurg Psychiatry 1981;44:176-8.

46 Tedeschi G, Allocca SD, DiCostanzo A, et al. Multisystem involvement of the central nervous system in Strümpell's involvement of the central nervous system in Strumpell's
disease. A neurophysiological and neuropsychological disease. A neurophysiological and
study. $\mathcal{F}$ Neurol Sci 1991;103:55-60. 